the instrument in February and March 1936, various kinds of researches were initiated, concurrently with observations for the establishment of a fundamental system of right ascensions. The work was interrupted in the autumn of 1940 owing to air attacks on London, and the objectives of the instrument and the two collimators and the micrometer eye-end were dismounted and removed to a place of safety. Fortunately sufficient material had been obtained and conclusions formed to guide the planning of post-war observations with the instrument.

The investigations have shown various ways in which systematic discordances of instrumental origin can enter into meridian observations, and the results may be useful to others who are planning a similar equipment. The paper gives the results of the investigation of the diurnal and seasonal changes of the instrumental errors of adjustment, and it is pointed out that a close control over the error of collimation will be essential when the instrument is brought into use again. A pronounced effect of wind directions on azimuth error has been shown to exist, the correction being a maximum, $0 \cdot 33^{\prime \prime}$, when the direction of the wind is north.

\section{Spot Gluing by High-Frequency Heating}

ONE of the advantages of high-frequency heating as applied to dielectrics is that it is very easily localized by the use of two small electrodes placed close together. Heating is confined to the material in the relatively strong electric field in the immediate neighbourhood of the gap between the electrodes. A pair of electrodes mounted in a suitable handle and connected by a flexible coaxial cable is sometimes used rather like a soldering iron for the gluing of joints in wood structures. Synthetic resin glues can be heated to the setting point in a few seconds. Another arrangement of electrodes in the form of two small wheels which roll over the opposite faces of sheets of material passing between them has been used as an 'electric sewing machine' for cementing together sheets of material.

Yet another device of this kind is a 'spot gluing' outfit recently developed by Pye Telecommunications, Ltd., in co-operation with Aero Research, Ltd. The electrodes are mounted in the form of a gun, the active electric field occupying the space between the end of the gun barrel and a central electrode coaxial with it. The central electrode is springmounted and projects slightly beyond the barrel, and pressure of the electrode on the work is made to operate switches, so that the power is automatically applied for an appropriate time interval, say, 2 sec. In operation, therefore, the process is closely analogous to spot welding, although it is used for tacking components into position when building up a complicated assembly, rather than for making complete joints. The importance of the process lies mainly in the fact that it holds out the possibility of dispensing with the use of brads, metal staples, clamps, etc., in forming some of the complex structures required in aircraft work.

\section{Crop Rotation}

AN entirely new and re-written edition of Bulletin No. 85, "Rotations", has been published by the Ministry of Agriculture and Fisheries (H.M. Stationery Office, 4d.). The author is Dr. H. G. Sanders of the School of Agriculture, Cambridge, as Prof. R. G. Whyte, writer of the previous editions, was unable to undertake the necessary revision. The principles of rotations are set out elearly, and the Norfolk fourcourse rotation, which had been followed for some two hundred years on the lighter soils of England, is discussed in some detail. During the last thirty years, however, this system has had to be radically altered to meet changed economic conditions, and cash crops of high value, such as sugar beet and potatoes, have been introduced. The extension of the rotation by means of the seeds ley is discussed, and a separate section is devoted to the special problems on heavy land, while catch-cropping forms the subject of the final section of the bulletin. Emphasis is laid on the fact that for successful farming a thorough understanding of traditional methods is the only sound basis for deviation from established practice.

\section{Chemotherapy and Tropical Medicine}

IN a lecture to the Chemical Society (J. Chem. Soc., $351 ; 1943)$, Dr. A. J. Ewins dealt with the above subject, and his lecture is particularly interesting in giving a concise historical account of the development of the use of chemical agents in the treatment of tropical diseases, which are caused not only by bacteria but also by virus, protozoal and parasitic infections. One of the first applications was in the treatment of sleeping sickness, in which the work of Ehrlich was predominant; for many years this field of investigation was one of the major concerns of the great German firms dealing with synthetic drugs, and these may be regarded as having taken a most prominent role in the welfare of parts of the world which otherwise looked to Great Britain as the proper source of research into matters so intimately affecting the Empire. Dr. Ewins is able to show, however, that a start has been made in overtaking the great gap between the development of research in chemotherapy in Britain and our responsibilities to the British Empire, and that the potentialities of such research are now being realized. The lecture is very concise and readable, and is recommended to the attention of all who may be concerned with Empire matters.

\section{U.S. National Vitamin Association}

THE organization in the United States of a National Vitamin Foundation was approved at a meeting of fifty representatives of all sections of the vitamin industry in New York on May 23 (.I. Amer. Med. Assoc., July 28). Its objects are to award grants for research in the vitamins or related fields, the dissemination of information in the vitamin trade, medical profession and public with respect to the quality, purposes and uses of vitamins, and to confer and consult with medical societies, medical schools, health organizations, public health agencies and government agencies with respect to vitamins and the vitamin industry. The Foundation will be administered by a board of trustees. Details of the organization are to be formulated by a committee of which Basil O'Connor, New York, president of the National Foundation for Infantile Paralysis, has been made chairman.

\section{Recent Earthquakes}

THE United States Coast and Geodetic Survey, in co-operation with Science Service and the Jesuit Seismological Association, has determined the epicentres of three recent earthquakes. The first was on June 28 at 7 h. $58.9 \mathrm{~m}$. G.M.T. with an epicentre at latitude $14 \cdot 6^{\circ} \mathrm{N}$., longitude $92 \cdot 6^{\circ} \mathrm{W}$., off southern 